\title{
Phase Equilibria of Sn-In Based Micro-Soldering Alloys
}

\author{
I. OHNUMA, ${ }^{1}$ Y. CUI, ${ }^{1}$ X. J. LIU, ${ }^{1}$ Y. INOHANA, ${ }^{1}$ S. ISHIHARA, ${ }^{2}$ \\ H. OHTANI, ${ }^{3}$ R. KAINUMA, ${ }^{1}$ AND K. ISHIDA ${ }^{1}$ \\ 1.-Tohoku University, Department of Materials Science, Graduate School of Engineering, \\ Aoba-yama 02, Sendai 980-8579, Japan. 2._Japan Science and Technology Co., Sendai 982-0807, \\ Japan. 3.-Tohoku University, Center for Interdisciplinary Research, Sendai 980-8578, Japan
}

\begin{abstract}
The phase equilibria of $\mathrm{Sn}-\mathrm{In}-\mathrm{X}(\mathrm{X}=\mathrm{Ag}, \mathrm{Bi}, \mathrm{Sb}, \mathrm{Zn})$, the most basic information necessary for the development of $\mathrm{Pb}$-free micro-soldering alloys, were studied using the CALPHAD method. Thermodynamic analyses for describing the Gibbs energies of the constituent phases were made by optimizing the obtained data on the experimental phase diagrams, and such data in the literature, including data on thermochemical properties. The present results combined with the thermodynamic database which was recently developed by our group [I. Ohnuma et al., J. Electron. Mater. 28, 1164 (1999)] provide various information on phase equilibria such as liquidus and solidus surfaces, isothermal and vertical section diagrams, mole fractions of the phase constitutions, etc., and thermodynamic properties such as activity, heat of mixing, surface energy, viscosity, etc., in multi-component soldering alloy systems including the elements of $\mathrm{Pb}, \mathrm{Bi}, \mathrm{Sn}$, $\mathrm{Sb}, \mathrm{Cu}, \mathrm{Ag}, \mathrm{Zn}$, and In. Typical examples for the phase diagrams and thermodynamic properties of Sn-In-X ternary systems are shown. The application of the database to the alloy design for Pb-free solders is also presented.
\end{abstract}

Key words: Phase equilibria, thermodynamics, database, Sn-In base alloys, Pb-free solders

\section{INTRODUCTION}

Although $\mathrm{Pb}-\mathrm{Sn}$ solders are widely used in electronic interconnections of packing technologies, further development of Pb-free solders is urgently required due to potential legislation which would ban or restrict the use of $\mathrm{Pb}$ in view of the environmental and health issues concerning its toxicity. We recently developed a thermodynamic database for the calculation of phase diagrams in micro-soldering alloy systems by the CALPHAD (CALculation of PHAse Diagrams) method; this database consists of the elements $\mathrm{Pb}, \mathrm{Bi}, \mathrm{Sn}, \mathrm{Sb}, \mathrm{Cu}, \mathrm{Ag}$, and $\mathrm{Zn} .^{1,2}$ The database provides various information on not only phase equilibria such as liquidus, solidus, equilibrium composition, volume fractions of constituent phases, etc., but also on thermochemical properties such as activity, heat of mixing, enthalpy of formation, surface energy,

(Received March 13, 2000; accepted April 25, 2000) viscosity, etc. Furthermore, the equilibrium and nonequilibrium solidification processes can be simulated. However, the important element In was not available at that time. In order to include In in this database, experimental and thermodynamic analyses of some Sn-In-base ternary alloys were carried out. The present paper shows the phase equilibria of Sn-In$\mathrm{X}$ (X: Ag, Bi, Sb, Zn) ternary systems, which are practically important for the development of the Pb-free solders. Some examples for the application of the thermodynamic database are also shown.

\section{THERMODYNAMIC DATABASE}

The database for calculating phase diagrams and thermodynamic properties has been constructed by use of the CALPHAD method..$^{3-5}$ The thermodynamic parameters for describing the Gibbs energy of the liquid and solid phases are evaluated by optimizing the experimental data on phase boundaries and thermochemical properties such as activity, heat of mix- 


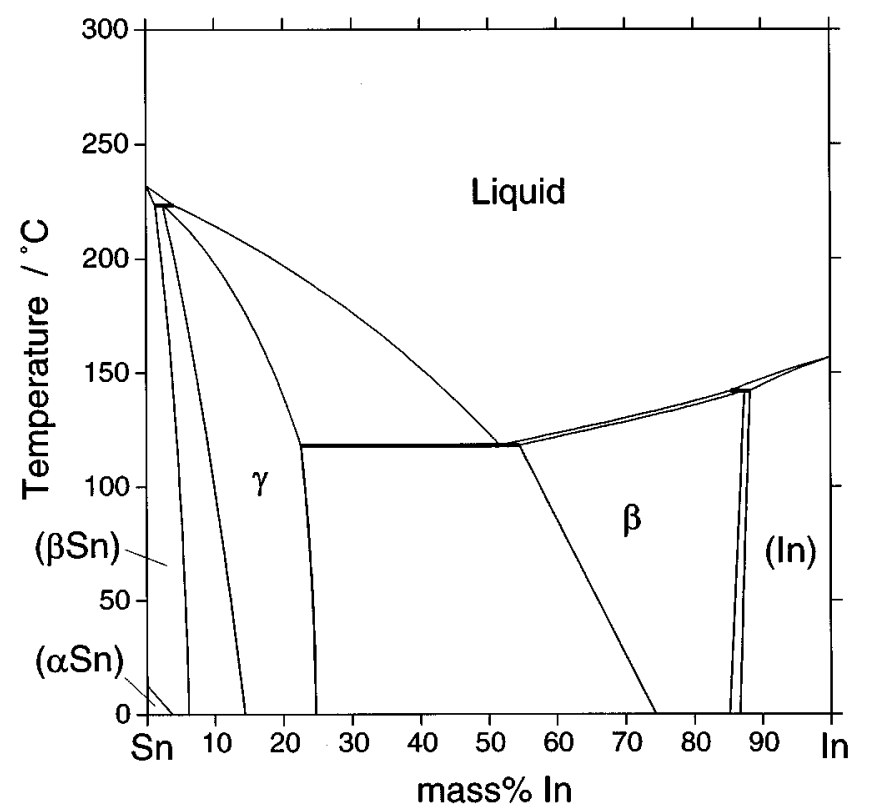

Fig. 1. Phase diagram of the Sn-In binary system.

ing and enthalpy of formation. The Gibbs energies of the liquid and solid solution phases are approximated by the regular solution model, while those of intermetallic phases with some solubility range are described by the sublattice model..$^{1,6,7}$

For some important alloy systems for which there are few data on phase boundaries, experimental determinations of phase equilibria were conducted using differential scanning calorimetry (DSC), energy dispersion x-ray spectroscopy (EDS), x-ray diffraction, and metallographic techniques. Moreover, additional experimental work was undertaken in some binary and ternary systems to check the reliability of the previous data reported before the 1950s. This

\begin{tabular}{lcc}
\hline & $\begin{array}{c}\text { Table I. Survey of Thermodynamic } \\
\text { Assessments of Binary Systems }\end{array}$ \\
\hline System & & Reference \\
\cline { 1 - 1 } Ag-In & & 8 \\
Ag-Sn & 9,10 \\
Bi-In & 11 \\
Bi-Sn & 7 \\
In-Sb & 12,13 \\
In-Sn & 14 \\
In-Zn & 15 \\
Sb-Sn & 7 \\
Sn-Zn & 10 \\
\hline
\end{tabular}

reconfirmation of the agreement between the calculated and the observed phase equilibria was required to obtain a better estimation of the thermodynamic parameters.

Table I shows a survey of thermodynamic assessments of binary systems consisting of Sn-In-X (X: Ag, $\mathrm{Bi}, \mathrm{Sb}, \mathrm{Zn}$ ) alloys that were carried out by our group $^{7,8,10,11,13}$ and also those previously reported. ${ }^{9,12,14,15}$ Figure 1 shows the calculated phase diagram of the Sn-In binary system, ${ }^{14}$ where the $\beta$ phase with the bctIn type crystal structure and the hexagonal $\gamma$ phase are formed. It should be noted that the assessment of the Ag-In binary system was made based on not only the previous data but also on new experimental results ${ }^{8}$ on the phase boundaries of the hexagonal $\zeta$ phase, where the homogeneous range of the $\zeta$ phase is more limited than that shown by the previous assessment. ${ }^{16}$

The thermodynamic assessments of ternaries are based on the results of the Sn-In-Ag, ${ }^{8} \mathrm{Sn}-\mathrm{In}-\mathrm{Bi},{ }^{11} \mathrm{Sn}-$ In-Sb, ${ }^{13}$ and Sn-In-Zn ${ }^{17}$ systems, where the thermodynamic parameters evaluated were arranged within the framework of the Thermo-Calc software. ${ }^{18}$

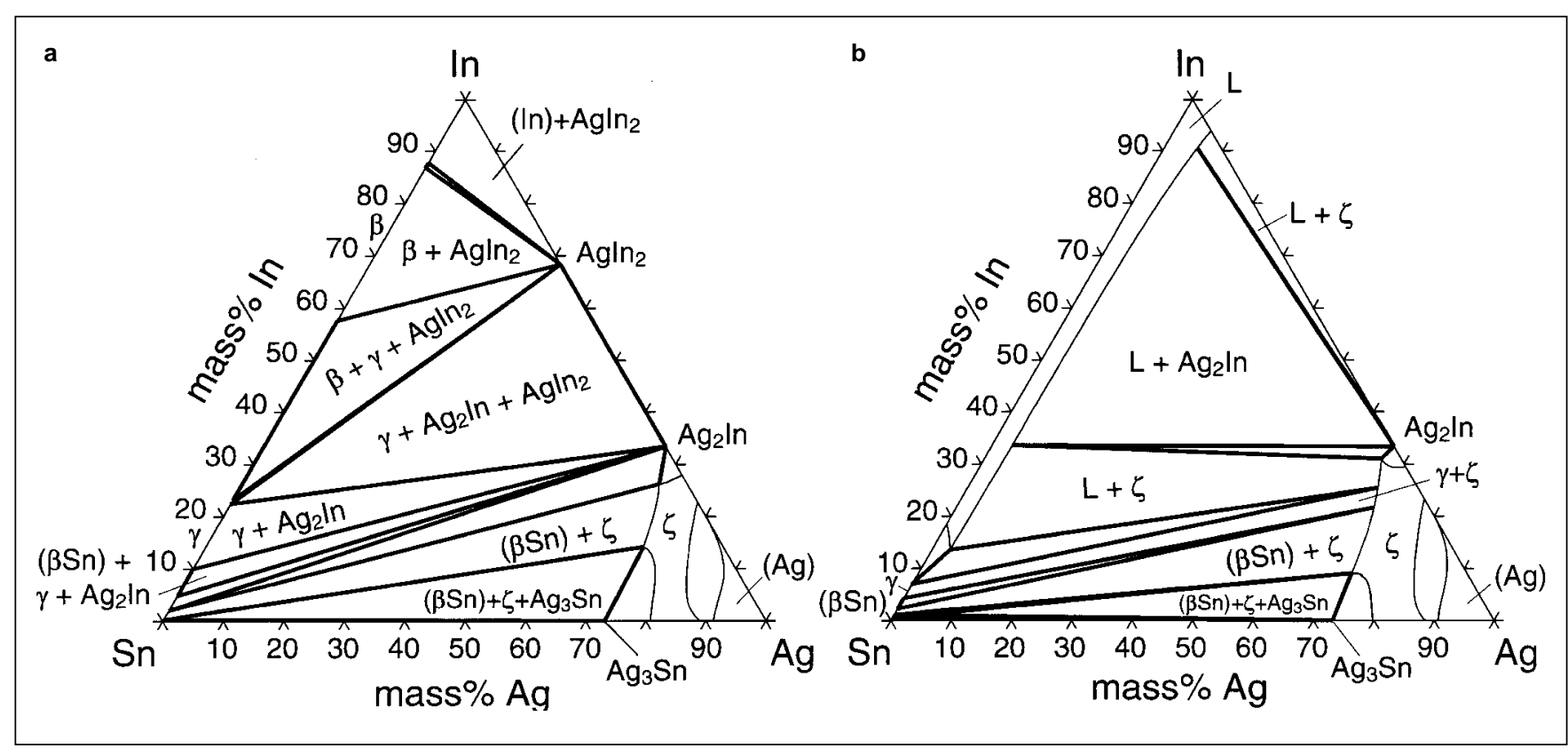

Fig. 2. Isothermal section diagrams of the Sn-In-Ag system at (a) $100^{\circ} \mathrm{C}$ and (b) $200^{\circ} \mathrm{C}$. 


\section{PHASE DIAGRAMS}

\section{Isothermal Sections}

Figures 2 to 5 show the calculated isothermal section diagrams of the Sn-In-Ag, Sn-In-Bi, Sn-In-Sb, and $\mathrm{Sn}-\mathrm{In}-\mathrm{Zn}$ systems at $100^{\circ} \mathrm{C}$ and $200^{\circ} \mathrm{C}$. It is shown that $\mathrm{Ag}$ and $\mathrm{Zn}$ have little solubility in the Sn-rich solid solution, while Bi exhibits a wide range of solubility. The greater solubility of $\mathrm{Bi}$ as well as In in the solid solution of the Sn-rich phase as shown in Fig. 1 is one of the reasons why the liquid phase remains at lower temperatures in the non-equilibrium solidification process $^{2} 11 b$.

\section{Vertical Sections}

Extensive effort has been made to develop lead-free solders, Sn-20mass\%In-X (X: Ag, Bi, Zn) alloys being suggested as possible alternatives to $\mathrm{Pb}-\mathrm{Sn}$ solders. ${ }^{19}$ Figure 6 shows the effect of the addition of $\mathrm{Ag}, \mathrm{Bi}, \mathrm{Sb}$, or $\mathrm{Zn}$ on the phase constitution of Sn-20mass\%In alloys.

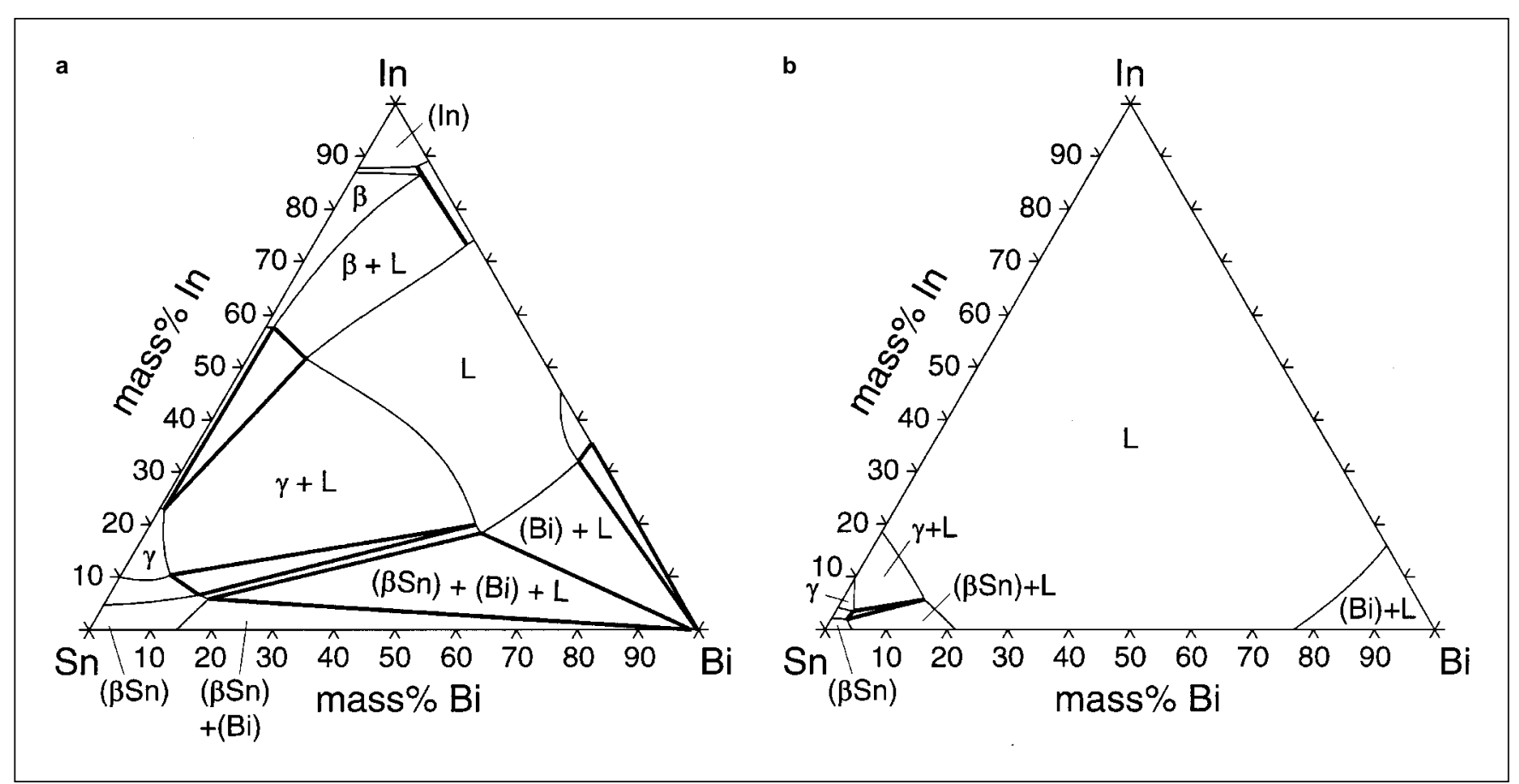

Fig. 3. Isothermal section diagrams of the $\mathrm{Sn}-\mathrm{In}-\mathrm{Bi}$ system at (a) $100^{\circ} \mathrm{C}$ and (b) $200^{\circ} \mathrm{C}$.

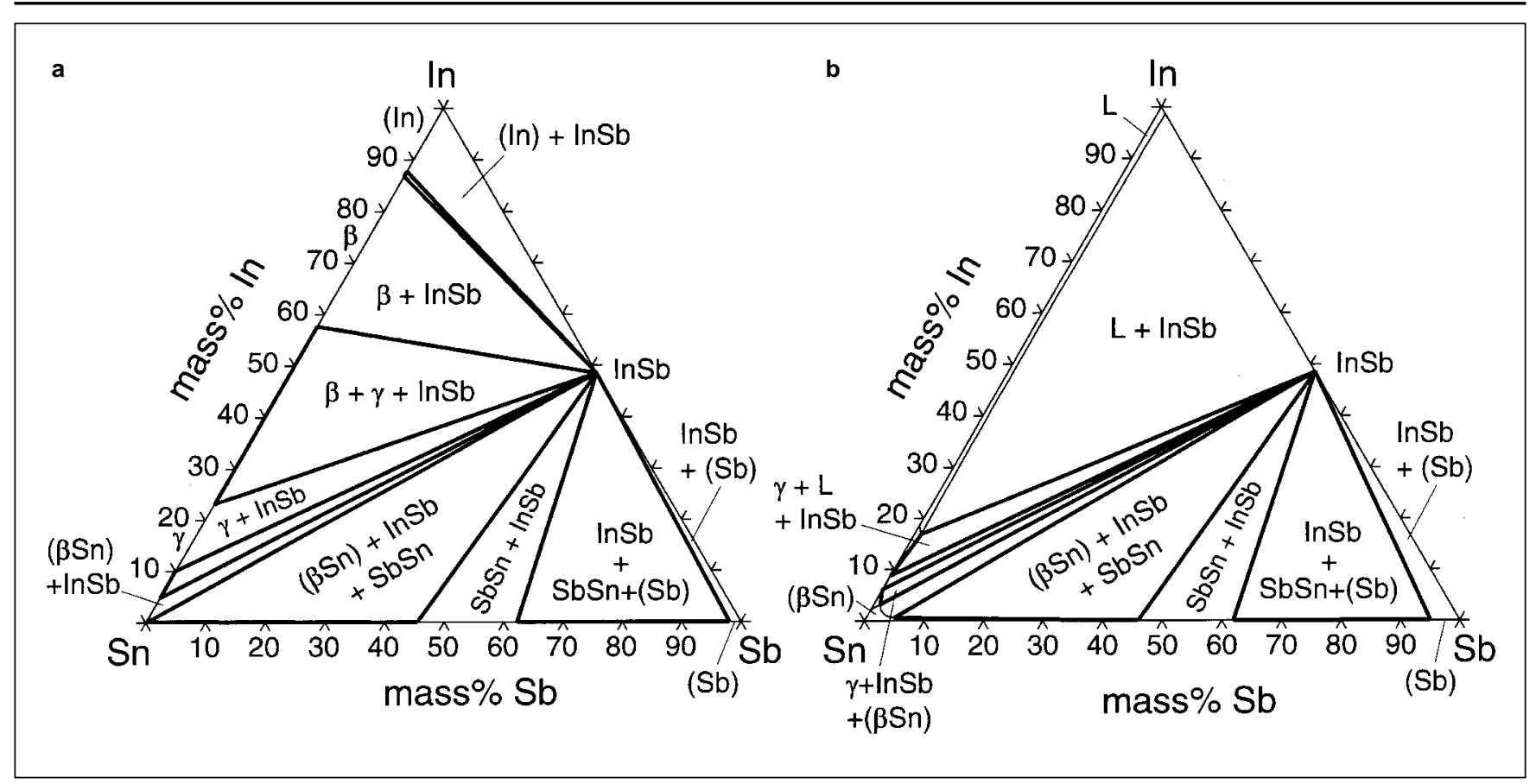

Fig. 4. Isothermal section diagrams of the Sn-In-Sb system at (a) $100^{\circ} \mathrm{C}$ and (b) $200^{\circ} \mathrm{C}$. 

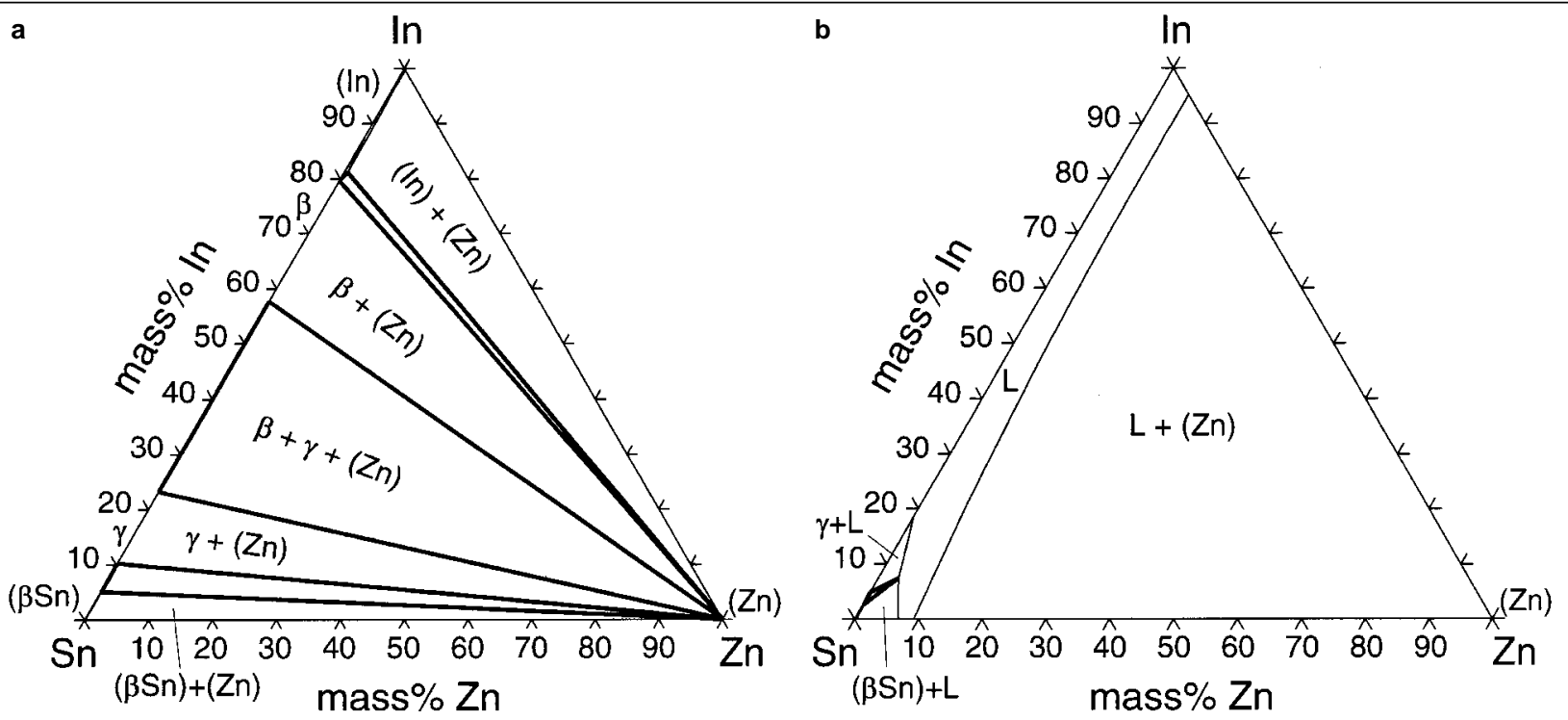

Fig. 5. Isothermal section diagrams of the Sn-In-Zn system at (a) $100^{\circ} \mathrm{C}$ and (b) $200^{\circ} \mathrm{C}$.
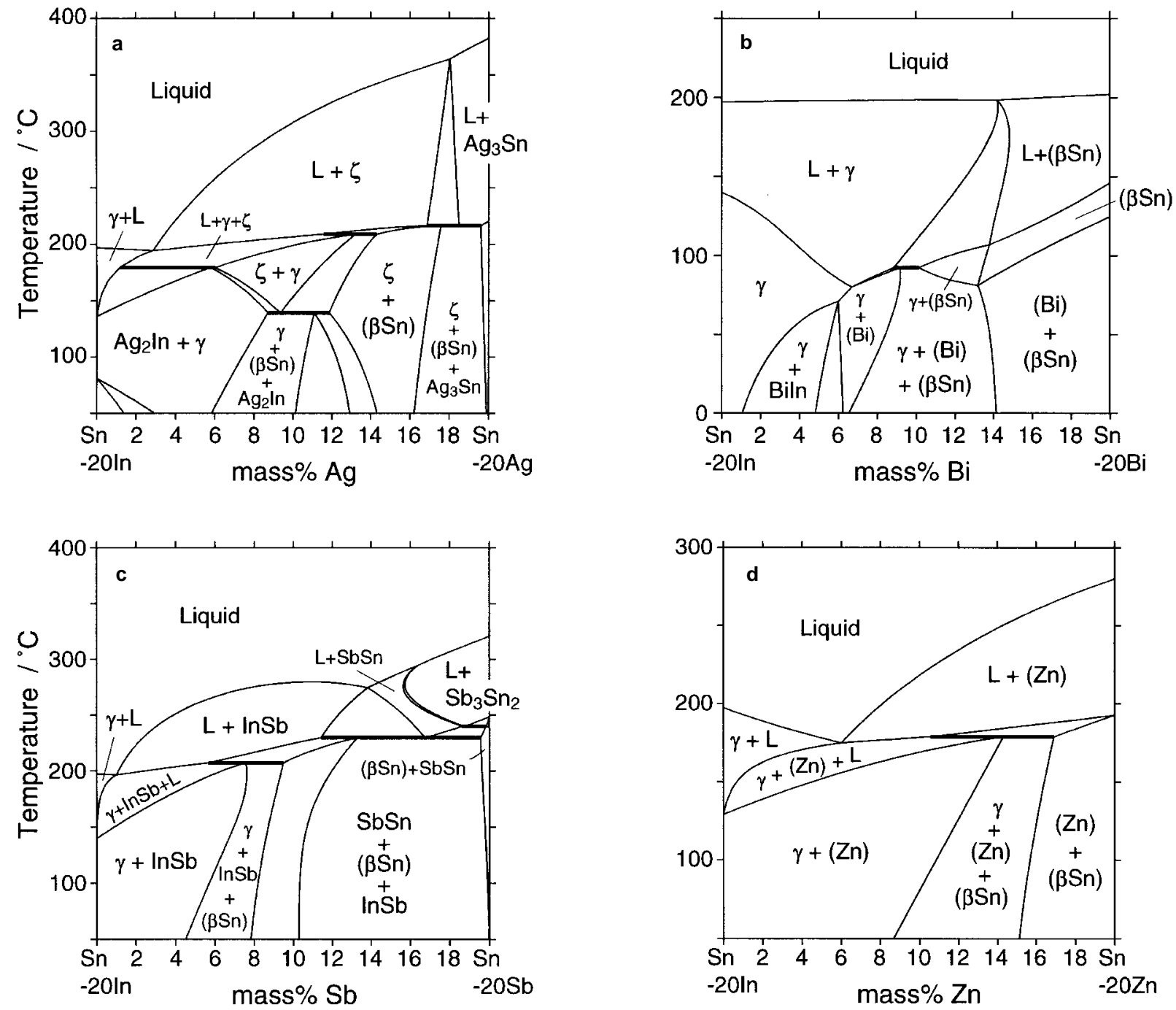

Fig. 6. Vertical section diagrams of the Sn-20mass\%In-X ternary system: $X=(a) A g$, (b) Bi, (c) Sb, and (d) Zn. 


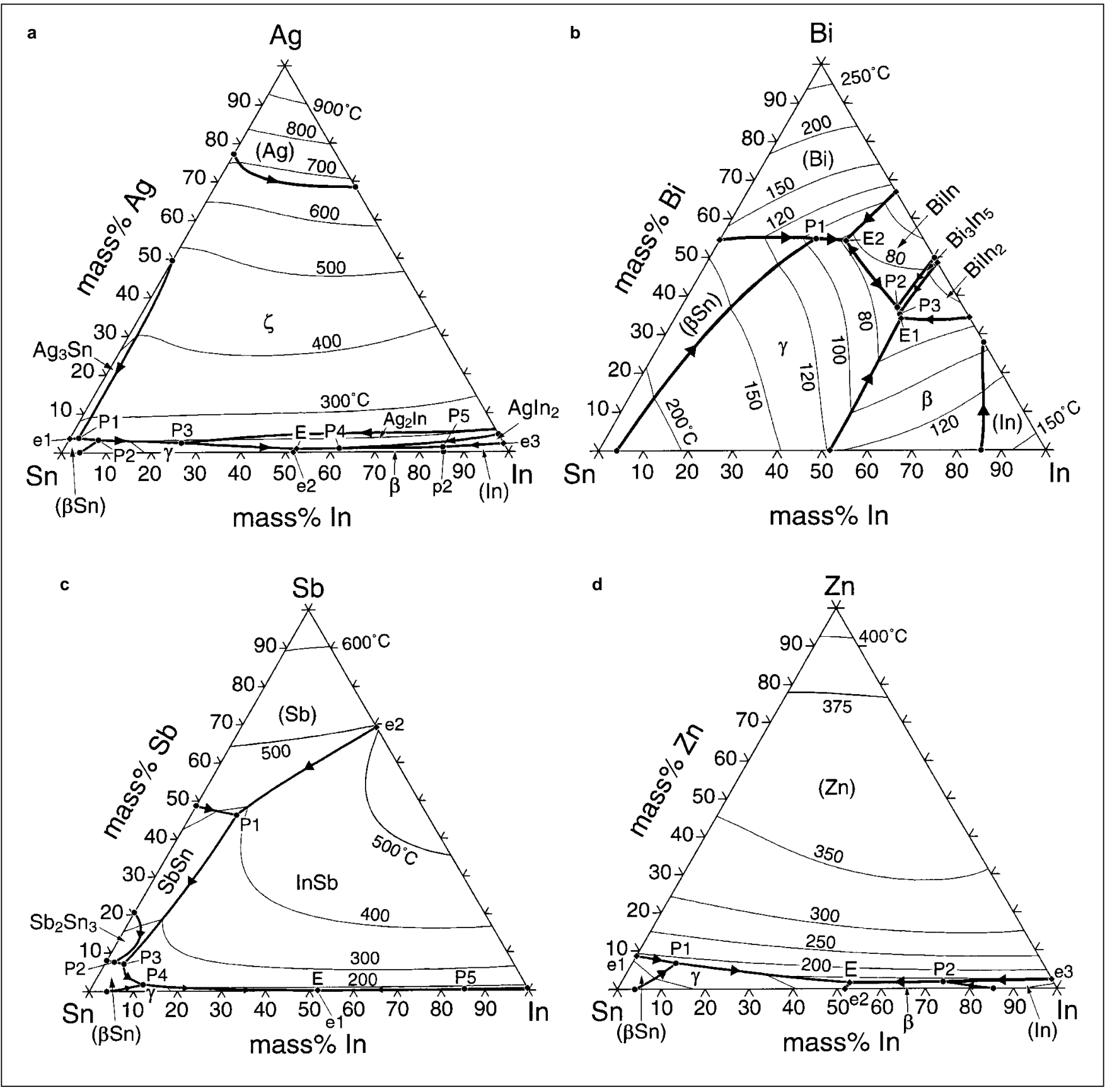

Fig. 7. Liquidus projections of the $\mathrm{Sn}-\mathrm{In}-\mathrm{X}$ ternary system: $\mathrm{X}=$ (a) $\mathrm{Ag}$, (b) $\mathrm{Bi}$, (c) $\mathrm{Sb}$, and (d) $\mathrm{Zn}$.

It is worthy of note that the developed Sn-20mass\%In2.8 mass $\% \mathrm{Ag} \mathrm{Pb}$-free solder alloy ${ }^{20}$ has the small temperature range of two-phase and three-phase fields containing a liquid phase as shown in Fig. 6a. The Sn20 mass \%In-6mass\%Zn alloy also has a small range of freezing temperatures desirable for the microstructure of solders, while the temperature range of the two-phase or three-phase fields accompanying the liquid phase is large in the Sn-20mass\%In-Bi alloys.

\section{Liquidus and Solidus}

The calculated liquidus projections of the four SnIn-base ternary systems are shown in Fig. 7. It can be seen that the melting temperature of the Sn-In-Bi system is very low, which is suitable for use in a system that requires low melting processing. Figure 8 shows the effect of $\mathrm{Ag}, \mathrm{Bi}, \mathrm{Sb}$, and $\mathrm{Zn}$ on the liquidus and solidus of the Sn-20mass\%In alloy. The liquidus temperature increases with increasing $\mathrm{Sb}$ and $\mathrm{Zn}$ concentration except for the case of low alloying content. As shown in Fig. 1, the eutectic reaction of the Sn-In binary system occurs at $51.7 \mathrm{mass} \% \mathrm{In}$ and $120^{\circ} \mathrm{C}$. Figure 9 shows the effect of $\mathrm{Ag}, \mathrm{Bi}, \mathrm{Sb}$, and $\mathrm{Zn}$ on the liquidus temperature of the Sn-51.7mass\%In eutectic alloy.

\section{Invariant Reactions}

It can be seen from the liquidus projection shown in Fig. 7 that various kinds of invariant reaction of 


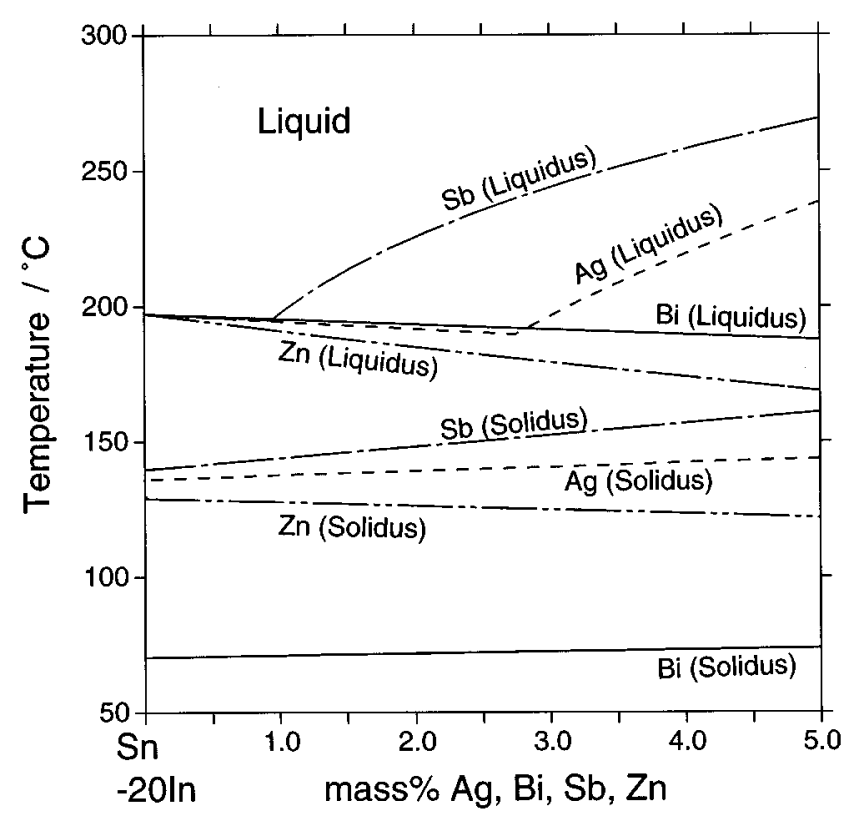

Fig. 8. Effects of $\mathrm{Ag}, \mathrm{Bi}, \mathrm{Sb}$, and $\mathrm{Zn}$ on the liquidus and solidus of $\mathrm{Sn}$ $20 \mathrm{mass} \%$ In alloy.

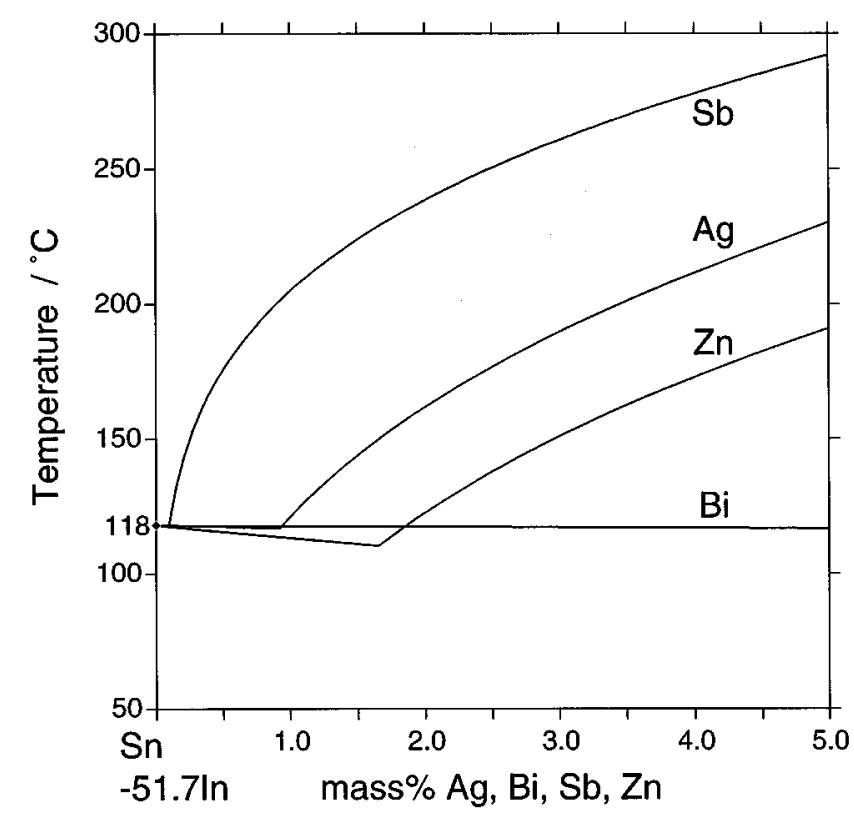

Fig. 9. Effects of $\mathrm{Ag}, \mathrm{Bi}, \mathrm{Sb}$, and $\mathrm{Zn}$ on the liquidus temperature of $\mathrm{Sn}$ $51.7 \mathrm{mass} \%$ In eutectic alloy.

Table II. Invariant Reactions of Sn-In-X (X = Ag, Bi, Sb, and Zn) Systems

\begin{tabular}{|c|c|c|c|c|c|}
\hline \multirow[t]{2}{*}{ System } & \multirow[t]{2}{*}{ Type } & \multirow[t]{2}{*}{ Reaction } & \multirow[t]{2}{*}{$\begin{array}{c}\text { Temperature } \\
\left({ }^{\circ} \mathbf{C}\right)\end{array}$} & \multicolumn{2}{|c|}{$\begin{array}{c}\text { Composition of the liquid } \\
\text { phase (mass } \% \text { ) }\end{array}$} \\
\hline & & & & In & $\mathbf{X}$ \\
\hline \multirow{6}{*}{ Sn-In-Ag } & $\mathrm{P} 1$ & $\mathrm{~L}+\mathrm{Ag}_{3} \mathrm{Sn} \Leftrightarrow(\beta \mathrm{Sn})+\zeta$ & 227 & 1.9 & 3.9 \\
\hline & $\mathrm{P} 2$ & $\mathrm{~L}+(\beta \mathrm{Sn}) \Leftrightarrow \gamma+\zeta$ & 209 & 6.8 & 3.3 \\
\hline & P3 & $\mathrm{L}+\zeta \Leftrightarrow \gamma+\mathrm{Ag}_{2} \mathrm{In}$ & 180 & 25.5 & 2.5 \\
\hline & $\mathrm{P} 4$ & $\mathrm{~L}+\mathrm{Ag}_{2} \operatorname{In} \Leftrightarrow \beta+\mathrm{AgIn}_{2}$ & 119 & 61.1 & 1.0 \\
\hline & $\mathrm{P} 5$ & $\mathrm{~L}+(\mathrm{In}) \Leftrightarrow \beta+\operatorname{AgIn}_{2}$ & 135 & 84.6 & 1.4 \\
\hline & $\mathrm{E}$ & $\mathrm{L} \Leftrightarrow \beta+\gamma+\mathrm{Ag}_{2} \operatorname{In}$ & 114 & 52.2 & 0.9 \\
\hline \multirow[t]{5}{*}{ Sn-In-Bi } & $\mathrm{P} 1$ & $\mathrm{~L}+(\beta \mathrm{Sn}) \Leftrightarrow(\mathrm{Bi})+\gamma$ & 93 & 21.4 & 23.9 \\
\hline & $\mathrm{P} 2$ & $\mathrm{~L}+\mathrm{BiIn} \Leftrightarrow \gamma+\mathrm{Bi}_{3} \mathrm{In}_{5}$ & 61 & 48.3 & 14.7 \\
\hline & P3 & $\mathrm{L}+\mathrm{Bi}_{3} \mathrm{In}_{5} \Leftrightarrow \gamma+\mathrm{BiIn}_{2}$ & 60 & 49.8 & 15.0 \\
\hline & $\mathrm{E} 1$ & $\mathrm{~L} \Leftrightarrow \gamma+\beta+\mathrm{BiIn}_{2}$ & 59 & 50.6 & 15.3 \\
\hline & $\mathrm{E} 2$ & $\mathrm{~L} \Leftrightarrow(\mathrm{Bi})+\gamma+\mathrm{BiIn}$ & 76 & 28.2 & 17.5 \\
\hline \multirow{6}{*}{ Sn-In-Sb } & $\mathrm{P} 1$ & $\mathrm{~L}+(\mathrm{Sb}) \Leftrightarrow \mathrm{InSb}+\mathrm{SbSn}$ & 388 & 10.4 & 46.3 \\
\hline & $\mathrm{P} 2$ & $\mathrm{~L}+\mathrm{Sb}_{2} \mathrm{Sn}_{3} \Leftrightarrow(\beta \mathrm{Sn})+\mathrm{SbSn}$ & 240 & 1.9 & 7.7 \\
\hline & P3 & $\mathrm{L}+\mathrm{SbSn} \Leftrightarrow(\beta \mathrm{Sn})+\mathrm{InSb}$ & 230 & 4.3 & 7.2 \\
\hline & $\mathrm{P} 4$ & $\mathrm{~L}+(\beta \mathrm{Sn}) \Leftrightarrow \gamma+\mathrm{InSb}$ & 207 & 11.4 & 1.8 \\
\hline & P5 & $\mathrm{L}+(\operatorname{In}) \Leftrightarrow \operatorname{InSb}+\beta$ & 141 & 85.2 & 0.3 \\
\hline & $\mathrm{E}$ & $\mathrm{L} \Leftrightarrow \operatorname{InSb}+\beta+\gamma$ & 118 & 51.8 & 0.1 \\
\hline \multirow[t]{3}{*}{ Sn-In-Zn } & $\mathrm{P} 1$ & $\mathrm{~L}+(\beta \mathrm{Sn}) \Leftrightarrow(\mathrm{Zn})+\gamma$ & 179 & 9.9 & 6.6 \\
\hline & $\mathrm{P} 2$ & $\mathrm{~L}+(\mathrm{In}) \Leftrightarrow(\mathrm{Zn})+\beta$ & 120 & 73.2 & 1.7 \\
\hline & $\mathrm{E}$ & $\mathrm{L} \Leftrightarrow(\mathrm{Zn})+\gamma+\beta$ & 107 & 52.2 & 1.6 \\
\hline
\end{tabular}

peritectic and eutectic type appear in the Sn-In-X ternary systems. Table II summarizes the reaction type, temperature and composition of the liquid phase in these systems. It is interesting to note that the invariant temperatures of $\mathrm{P} 3\left(180^{\circ} \mathrm{C}\right)$ of Sn-In-Ag and of $\mathrm{P} 1\left(179^{\circ} \mathrm{C}\right)$ of $\mathrm{Sn}-\mathrm{In}-\mathrm{Zn}$ systems are very close to the $\mathrm{Pb}-\mathrm{Sn}$ eutectic temperature $\left(183^{\circ} \mathrm{C}\right)$.

\section{APPLICATIONS OF DATABASE}

The thermodynamic database allows prediction of various aspects involved in the development of $\mathrm{Pb}$ - free solders. Some applications of the database are shown here. Figure 10a shows the calculated vertical section of Sn-In-Zn alloys with constant 9 mass $\% \mathrm{Zn}$ including the experimental data, ${ }^{21-23}$ where the Sn9 mass $\% \mathrm{Zn}$ binary alloy is very close to the binary eutectic composition. Figure 10b shows the effect of In on the Sn-Zn eutectic alloy in the e1-P1 cross section of Fig. $7 \mathrm{~d}$. It is obvious that the binary Sn-Zn eutectic reaction is suitably depressed with increasing In content until the ternary peritectic reaction $\mathrm{P} 1$ is reached. A very similar phase reaction can be found in 


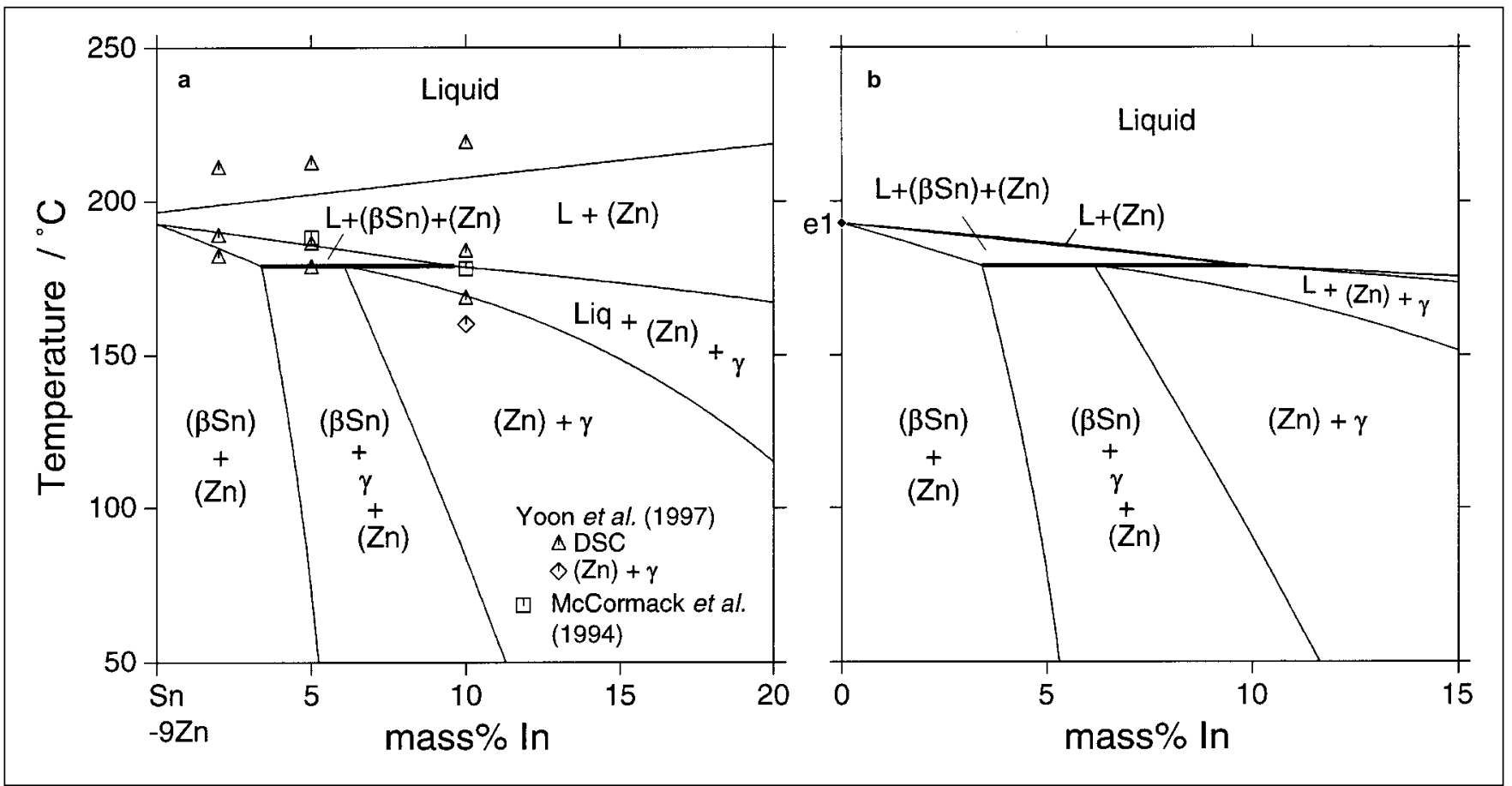

Fig. 10. Vertical section diagram of the Sn-In-Zn ternary system: (a) 9 mass $\%$ Zn and (b) e1-P1 cross section of Fig. $7 d$.

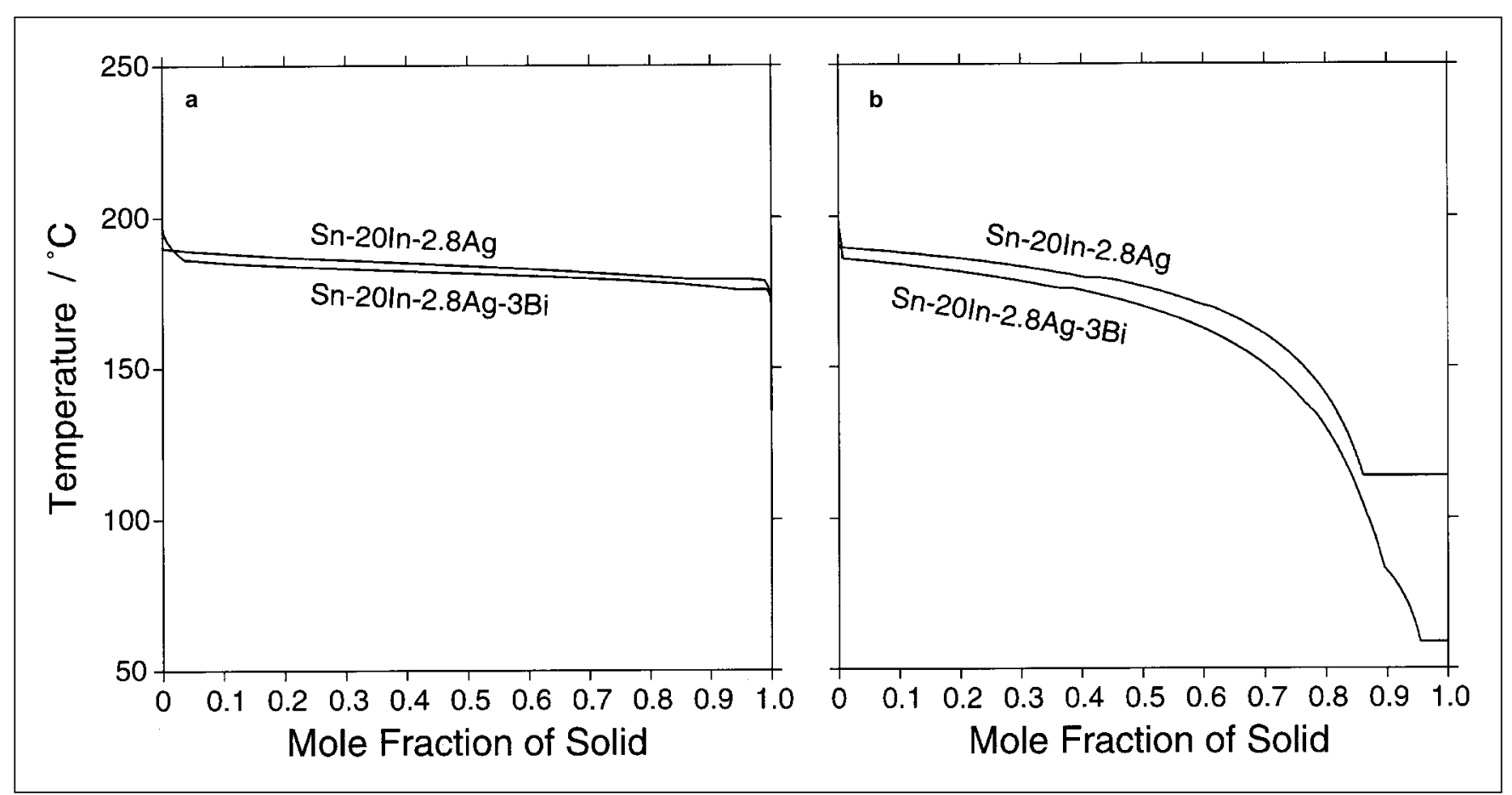

Fig. 11. Phase fraction of solid vs. temperature of Sn-20mass\%ln-2.8mass\%Ag and Sn-20mass\%ln-2.8mass\%Ag-3mass\%Bi: (a) equilibrium solidification and (b) non-equilibrium solidification by the Scheil model.

the vertical section of Fig. 10a. It should be emphasized, however, that the respective effects of In addition on the liquidus temperature and the freezing range are remarkably different; the incorporation of In increases the liquidus temperature and the temperature range of the two or three-phase field accompanying the liquid phase at 9 mass $\% \mathrm{Zn}$, while it decreases both features in the cross section of e1-P1.
These facts suggest that the alloys within the range of 2-5 mass\%In located at the e1-P1 line, characterized by the similarity of their melting behavior to that of the $\mathrm{Sn}-\mathrm{Pb}$ eutectic alloy, are more suitable for $\mathrm{Pb}$-free solders than the Sn-9mass\%Zn-(2-5)mass\%In alloys. These calculations provide important information for use in the design of new solder alloys.

Another application of the thermodynamic data- 

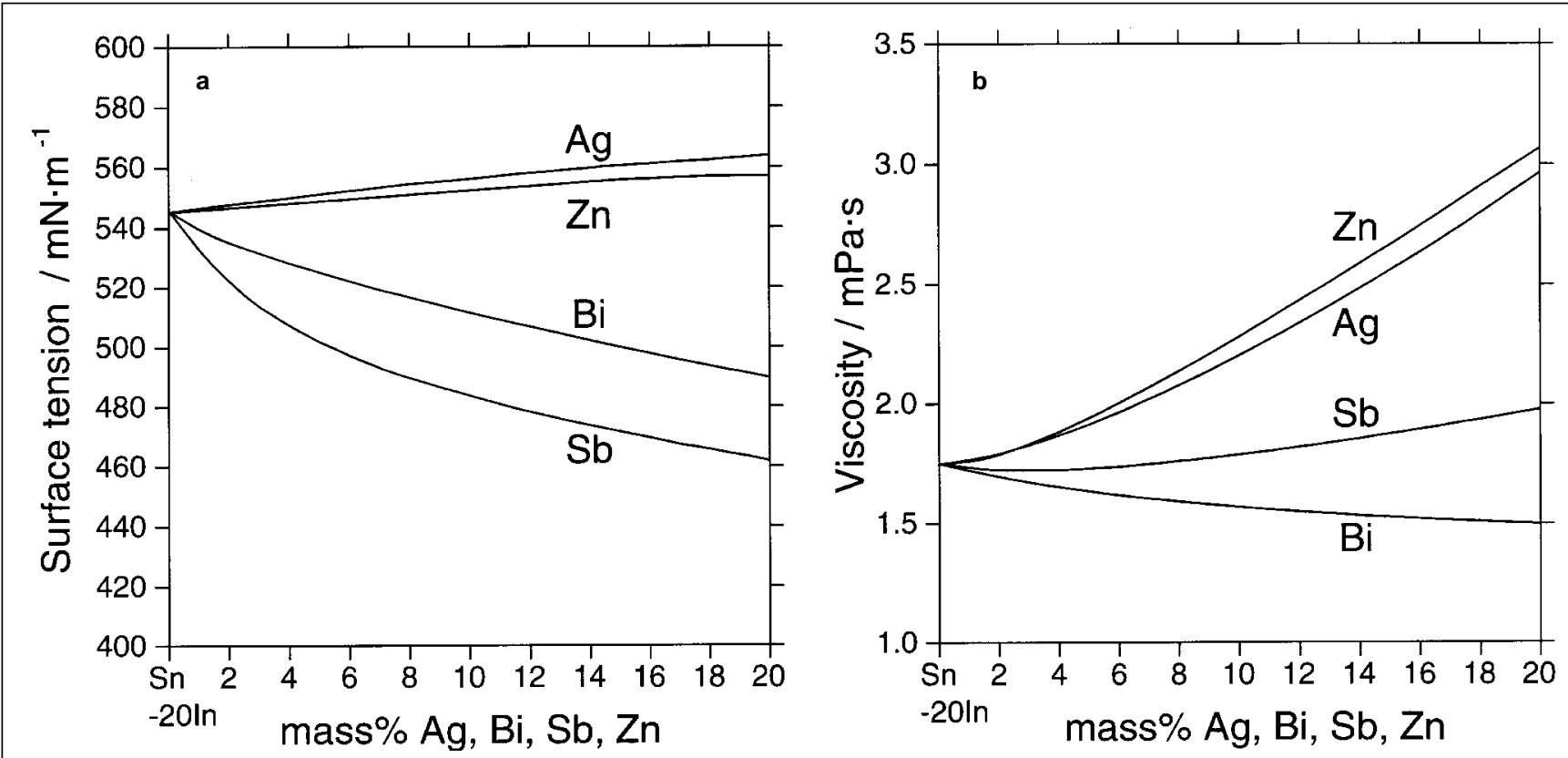

Fig. 12. Effects of $\mathrm{Ag}, \mathrm{Bi}, \mathrm{Sb}$, and $\mathrm{Zn}$ on the (a) surface tension and (b) viscosity of $\mathrm{Sn}-20 \mathrm{mass} \% \mathrm{In}$ alloy at $250^{\circ} \mathrm{C}$.

base is the simulation of the solidification process. Although the Scheil model assumes that local equilibrium exists at the liquid/solid interface and diffusion is absent in the solid phase, Scheil calculation can still provide a prediction close to reality. Figure 11a and $b$ show the calculated phase fraction ${ }^{22}$ of solid vs. temperature variation of $\mathrm{Sn}-20 \mathrm{mass} \% \mathrm{In}-2.8 \mathrm{mass} \% \mathrm{Ag}^{20}$ and $\mathrm{Sn}-20 \mathrm{mass} \% \mathrm{In}-2.8 \mathrm{mass} \% \mathrm{Ag}-3 \mathrm{mass} \% \mathrm{Bi}^{22}$ alloys under equilibrium and non-equilibrium solidification conditions, respectively. In comparison with the equilibrium solidification based on the lever rule, the formation of the liquid phase due to segregation in the Scheil calculation increases the freezing range. In particular, the addition of Bi strongly causes liquid formation at low temperature. The presence of the liquid phase at these temperatures due to non-equilibrium solidification is considered to be one of the reasons for the lifting-off phenomenon between the solder and the $\mathrm{Cu}$ substrate. ${ }^{24}$

The surface tension and viscosity of the liquid phase can also be calculated using thermodynamic models ${ }^{25-27}$ where the estimation is based on the Gibbs energy of the liquid phase. Figure $12 \mathrm{a}$ and $\mathrm{b}$ show the effect of $\mathrm{Ag}, \mathrm{Bi}, \mathrm{Sb}$, and $\mathrm{Zn}$ on the surface tension and viscosity of the Sn-20mass\%In alloy at $250^{\circ} \mathrm{C}$, respectively. It can be seen that $\mathrm{Ag}$ and $\mathrm{Zn}$ increase both the surface tension and viscosity. This kind of information would be useful when considering the melting behavior, castability and manufacturability of solders.

\section{CONCLUDING REMARKS}

The phase equilibria of the Sn-In-X (X: Ag, Bi, Sb, and $\mathrm{Zn}$ ) systems were studied. Thermodynamic assessments of these systems were also carried out and the resulting data were incorporated in the thermo- dynamic database which was recently developed by our group..$^{1,2}$ The phase diagrams of Sn-In base alloys and their application to the design and development of $\mathrm{Pb}$-free solders using the database were presented. The validity and applicability of this database can be expected to be a powerful tool for solder technology.

\section{ACKNOWLEDGEMENT}

The authors wish to thank the support from Casio Science Promotion.

\section{REFERENCES}

1. I. Ohnuma, X.J. Liu, H. Ohtani, and K. Ishida, J. Electron. Mater. 28, 1164 (1999).

2. I. Ohnuma, X.J. Liu, H. Ohtani, and K. Ishida, Functional Materials, ed. K. Grassie et al. (Weinheim, Germany: WileyVCH, 2000), p. 69.

3. U.R. Kattner, JOM 49, 14 (1997).

4. H. Ohtani and K. Ishida, Themochemica Acta 214, 69 (1998).

5. N. Saunders and A.P. Miodwnik, CALPHAD (Lausanne, Switzerland: Pergamon, 1998).

6. M. Hillert and L.I. Staffansson, Acta Chem. Scand. 24, 3618 (1970).

7. H. Ohtani and K. Ishida, J. Electron. Mater. 23, 747 (1994).

8. Y. Inohana, X.J. Liu, I. Ohnuma, R. Kainuma, and K. Ishida, Abstracts of the Jpn. Inst. Metals 125, 368 (1999).

9. U.R. Kattner and W. Boettinger, J. Electron. Mater. 23, 603 (1994).

10. H. Ohtani, M. Miyashita, and K. Ishida, J. Jpn, Inst. Met. 63, 685 (1999).

11. Y. Cui, T. Ishihara, X.J. Liu, I. Ohnuma, H. Ohtani, and K. Ishida, submitted to J. Alloys and Comp.

12. I. Ansara, C. Chatillon, H.L. Lukas, T. Nishizawa, H. Ohtani, K. Ishida, M. Hillert, B. Sundman, B.B. Argent, A. Watson, T.G. Chart, and T. Anderson, CALPHAD 18, 177 (1994).

13. T. Ishihara, H. Ohtani, T. Saito, and K. Ishida, J. Jpn. Inst. Met. 63, 695 (1999).

14. B.J. Lee, C.S. Oh, and J. Hao Shim, J. Electron. Mater. 25, 983 (1996).

15. B.J. Lee, CALPHAD 20, 471 (1996).

16. M.R. Baron, Phase Diagrams of Indium Alloys and Their 
Engineering Applications, ed. C.E.T. White and H. Okamoto (Materials Park, OH: ASM Int., 1992), p. 15.

17. Y. Cui, X.J. Liu, I. Ohnuma, R. Kainuma, H. Ohtani, and K. Ishida, submitted to J. Alloys and Comp.

18. B. Sundman, B. Jansson, and T.O. Anderson, CALPHAD 9, 153 (1985).

19. Lead-Free Solder Project, Final Report (Ann Arbor, MI: National Center for Manufacturing Science, 1997).

20. I. Artaki and A.M. Jackson, J. Electron. Mater. 23, 757 (1994).

21. M. McCormack and S. Jin, J. Electron. Mater. 23, 635 (1994).
22. M. McCormack, S. Jin, and H.S. Chen, J. Electron Mater. 23, 687 (1994).

23. S.W. Yoon, J.R. Soh, B.J. Lee, and H.M. Lee, Design and Reliability of Solders and Solders Interconnections, ed. R.K. Mahidhara, D.R. Frear, S.M.K. Saty, K.L. Murty, P.K. Liaw, and W. Winterbottom (Warrendale, PA: TMS, 1997), p. 121.

24. K. Suganuma, J. Jpn. Electro. Packaging 2, 116 (1999).

25. J.A.V. Butler, Proc. Royal Soc. London A135, 348 (1932).

26. T. Tanaka and I. Iida, Steel Research 65, 21 (1994).

27. S. Seetharaman and D. Sichen, Metall. Mater. Trans. B 25B, 589 (1994) 